\title{
4.20 Reduced-risk insecticides in Neotropical stingless bee species: impact on survival and activity
}

\section{Hudson Vaner V. Tomé1, Wagner F. Barbosa ${ }^{1,2}$, Alberto S. Corrêa ${ }^{3}$, Lessando M. Gontijo ${ }^{4}$, Gustavo F. Martins ${ }^{5}$, Raul Narciso C. Guedes ${ }^{1}$}

${ }^{1}$ Departamento de Entomologia, Universidade Federal de Viçosa, Viçosa, Minas Gerais, Brazil

${ }^{2}$ Department of Crop Protection, Faculty of Bioscience Engineering, Ghent University, Ghent, Belgium

${ }^{3}$ Departamento de Entomologia e Acarologia, Escola Superior de Agricultura "Luiz de Queiroz", Universidade de São Paulo, Piracicaba, São Paulo, Brazil

${ }^{4}$ Instituto de Ciências Agrárias, Universidade Federal de Viçosa, Campus Florestal, Florestal, Minas Gerais, Brazil ${ }^{5}$ Departamento de Biologia Geral, Universidade Federal de Viçosa, Viçosa, Minas Gerais, Brazil

Corresponding author:Raul Narciso C. Guedes, Departamento de Entomologia, Universidade Federal de Viçosa, Viçosa, MG 36570-900, Brazil, Tel. +55 (31) 3899-4008, E-mail: barbosawf@gmail.com

\begin{abstract}
Background: As honeybees are the main pollinator species subject to an intense research regarding effects of pesticides, other ecologically important native bee pollinators have received little attention in ecotoxicology and risk assessment of pesticides in general, and insecticides in particular, some of which are perceived as reduced-risk compounds. Here the impact of three reduced-risk insecticides - azadirachtin, spinosad, and chlorantraniliprole - was assessed in two species of stingless bees, Partamona helleri and Scaptotrigona xanthotrica, which are important native pollinators in Neotropical America. The neonicotinoid imidacloprid was used as a positive control.
\end{abstract}

Results: Spinosad exhibited high oral and contact toxicities in adult workers of both species at the recommended label rates, with median survival times $\left(L_{50} s\right)$ ranging from 1 to $4 \mathrm{~h}$, whereas these estimates were below $15 \mathrm{~min}$ for imidacloprid. Azadirachtin and chlorantraniliprole exhibited low toxicity at the recommended label rates, with negligible mortality that did not allow $\mathrm{LT}_{50}$ estimation. Sublethal behavioral assessments of these two insecticides indicated that neither one of them affected the overall group activity of workers of the two species. However, both azadirachtin and chlorantraniliprole impaired individual flight take-off of $P$. helleri and $S$. xanthotrica worker bees, which may compromise foraging activity, potentially leading to reduced colony survival.

Conclusion: These findings challenge the common perception of non-target safety of reduced-risk insecticides and bioinsecticides, particularly regarding native pollinator species.

Keywords: behavioral impact; biopesticides; colony and individual level effects; native bee pollinators; sublethal effects.

1. IntroductionThe honeybee is perceived as very sensitive to insecticides compared to other arthropod species. ${ }^{1-3}$ Therefore this species has for some time been the representative model pollinator because it is widely available globally and inexpensive to use as an environmental bioindicator of pesticide pollution. 3,4 However, a recent meta-analysis study provided support for such use of honeybees, a 10-fold sensitivity ratio correction seems necessary for the extrapolation of insecticide toxicity results from the honeybee to other bee species. ${ }^{5}$ Such fact has obscured the importance of stingless bees and only little research has undertaken on this topic. ${ }^{5-8}$

Stingless bees species are the primary pollinators of wild and cultivated plants in Neotropical America ${ }^{9-12}$ and they may be important even in the presence of the honeybee. ${ }^{5,8,9}$ Therefore, stingless bees demand more attention regarding the potential effects of pesticides in this particular geographic region. Furthermore, the reliance on the honeybee for insecticide toxicity assessments may compromise more susceptible pollinator species, such as stingless bees, and thus impair agricultural production and plant diversity in the neotropics. $4,13,14$

The general focus on the impact of neonicotinoids on pollinators, particularly honeybees, has led to an expansion and incentives of reduced-risk pesticides and particularly of biopesticides. ${ }^{15-18}$ The 
encouragement for the use of such compounds is illustrated by European Pesticide Regulation No. 1107/2009/EC and Directive 2009/128/EC of the European Parliament and of the Council in addition to similar regulatory efforts in Canada, the USA, and elsewhere. ${ }^{17,19,20}$ Nonetheless, reduced-risk insecticides may still be highly toxic and represent a high risk to non-target beneficial insects such as stingless bees, which are completely neglected in ecotoxicology and riskassessment studies. Furthermore, biopesticides are not necessarily safer than synthetic pesticides, because origin is not a determinant of toxicity or risk. ${ }^{21-24}$

Considering the shortcomings regarding toxicological and ecotoxicological assessments on nonApis bee species, such stingless bees, and reduced-risk (bio)insecticides as presented above, here we hypothesized that the oral and contact (acute) toxicity of the recommended label rates of a reduced-risk insecticide (chlorantraniliprole), a bioinsecticide (azadirachtin), and a reduced-risk bioinsecticide (spinosad) might compromise the survival of two species of stingless bees, Partamona helleri (Friese) and Scaptotrigona xanthotrica (Moure) (Hymenoptera: Apidae: Meliponini). Such stingless bees' species are important native pollinators in the Neotropical America. ${ }^{10-13,25}$ The group activity and flight take-off of adult workers exposed to azadirachtin or chlorantraniliprole were also assessed for impact prediction on behavior of both native bee species.

\section{Materials and methods}

\subsection{Insects and insecticides}

Three colonies of each of the stingless bee species P. helleri (ca. 1,000-3,000 individuals/colony) and S. xanthotrica (over 10,000 individuals/colony) were collected in Viçosa county (State of Minas Gerais, Brazil; $20^{\circ} 45^{\prime} \mathrm{S}$ and $42^{\circ} 52^{\prime} \mathrm{W}$ ) and maintained in the experimental apiary of the Federal University of Viçosa. The adult workers of each species were collected as groups of 10 individuals per colony at the hive entrance of their respective colonies in the experimental apiary using glass jars when they exit the hive to forage. They were subsequently taken to the laboratory and maintained without food inside wooden cages covered with organza $(35 \times 35 \times 35 \mathrm{~cm})$ for $1 \mathrm{~h}$ at 25 $\pm 2^{\circ} \mathrm{C}, 70 \pm 10 \% \mathrm{RH}$, and total darkness until the bioassays were initiated. The waiting period before exposure was necessary to standardize the feeding condition of the tested workers.

Three insecticides were used in their respective commercial formulations as follows: azadirachtin (emulsifiable concentrate at $12 \mathrm{~g} \mathrm{litre}^{-1}$, DVA Agro Brasil, Campinas, SP, Brazil), chlorantraniliprole (suspension concentrate at $200 \mathrm{~g}$ litre $^{-1}$, DuPont do Brasil, Barueri, SP, Brazil), and spinosad (suspension concentrate at $480 \mathrm{~g} \mathrm{litre}^{-1}$, Dow AgroSciences, Santo Amaro, SP, Brazil). The neonicotinoid imidacloprid (water dispersible granules at $700 \mathrm{~g} \mathrm{~kg}^{-1}$, Bayer CropScience, São Paulo, SP, Brazil) was used as a positive control due to its high and widely recognized toxicity to bee pollinators. ${ }^{5,6,26}$ The insecticides were used at rates calculated based on the spray volume per hectare (azadirachtin: $1000 \mathrm{I} \mathrm{ha}^{-1}$, chlorantraniliprole: $1000 \mathrm{I} \mathrm{ha}^{-1}$, spinosad: $400 \mathrm{I} \mathrm{ha}{ }^{-1}$, imidacloprid: $333 \mathrm{I} \mathrm{ha}^{-1}$ ) for the control of the white fly Bemisia tabaci (Gennadius) (Hemiptera: Sternorrhyncha: Aleyrodidae) and the tomato pinworm Tuta absoluta (Meyrick) (Lepidoptera: Gelechiidae) on tomato crops in accordance with the recommendations of the Brazilian Ministry of Agriculture. ${ }^{26}$ The insecticide formulations were diluted either in distilled and deionized water (contact exposure bioassays) or in an aqueous sucrose solution $500 \mathrm{~g} \mathrm{~kg}^{-1}$ (for oral exposure bioassays) at the following concentrations based on the maximum field label rates registered for each insecticide: azadirachtin at $30 \mathrm{mg}$ litre $\mathrm{e}^{-1}$, chlorantraniliprole at $3 \mathrm{mg} \mathrm{litre}^{-1}$, imidacloprid at $42 \mathrm{mg} \mathrm{litre} \mathrm{e}^{-1}$, and spinosad at $20.4 \mathrm{mg} \mathrm{litre}^{-1}{ }^{26}$

\subsection{Time-mortality residual contact bioassays}

Inner walls of transparent low-density polyethylene plastic containers (volume of $250 \mathrm{~mL}$ and inner surface of $365.43 \mathrm{~cm}^{2}$ ) with negligible sorption and resistant to organic chemicals under short-term exposure ${ }^{27,28}$ were treated with $500 \mu$ l of insecticide solution (or water, in the case of 
the control) using an artist's air brush (Sagyma SW440A, Yamar Brasil, São Paulo, SP, Brazil) coupled with an air pump (Prismatec 131A Tipo 2 VC, Itu, SP, Brazil) at a pressure of $6.9 \times 10^{4} \mathrm{~Pa}$. The insecticide-sprayed containers were allowed to dry for $2 \mathrm{~h}$ under a fume hood at $25 \pm 3^{\circ} \mathrm{C}$ without incidence of direct light, after which 10 adult workers were released within each container and retained by covering the top with organza fabric. Three containers (replicates), one per colony of each species, were used. Untreated sucrose solution was provided in a feeder to the bees through a hole in the plastic containers. After a 3-h exposure, the insects were transferred to untreated containers with $1 \mathrm{~mL}$ of sucrose solution at $500 \mathrm{~g} \mathrm{~kg}^{-1}$. Bee survival was recorded hourly for $24 \mathrm{~h}$ from the beginning of the residual contact exposure. The insects were considered dead when they were unable to walk the length of their body and no insect recognized as dead by such criteria was able to recover in the study.

\subsection{Time-mortality ingestion bioassays}

Low-density plastic containers $(250 \mathrm{ml})$ were again used as experimental units containing 10 worker bees fed on $500 \mu \mathrm{l}$ of insecticide-contaminated sucrose solution (except for untreated controls) in longitudinally cut Eppendorf tubes used as plastic feeders and inserted through a hole in the plastic container. The insecticide dose ingested was obtained by weighing the feeders before and after the experiment. The oral ingestion of insecticide-contaminated sucrose solution $\left(500 \mathrm{mg} \mathrm{kg}^{-1}\right.$ ) by each 1-h starved bee species (between 0.69 and $1.12 \mu \mathrm{l}$ adult worker ${ }^{-1}$ of $P$. helleri, and between 0.52 and $0.77 \mu$ ladult worker ${ }^{-1}$ of S. xanthotrica) led to the following ingested doses of insecticide per worker: $P$. helleri - $25.80 \mathrm{ng}$ bee of azadirachtin, $2.84 \mathrm{ng} \mathrm{bee}^{-1}$ of chlorantraniliprole, $28.90 \mathrm{ng}_{\text {bee }}^{-1}$ imidacloprid, and $22.79 \mathrm{ng} \mathrm{bee}^{-1}$ of spinosad; and S. xanthotrica $15.48 \mathrm{ng}$ bee $^{-1}$ of azadirachtin, $2.06 \mathrm{ng} \mathrm{bee}^{-1}$ of chlorantraniliprole, $25.28 \mathrm{ng}^{-1}$ bee $^{-1}$ imidacloprid, and $15.82 \mathrm{ng} \mathrm{bee}{ }^{-1}$ of spinosad. Three containers (replicates), one per colony of each species, were used. Bee survival was recorded as previously described for the contact bioassays.

\subsection{Group activity}

Bioassays of the overall group activity of workers of both stingless bee species were performed 24 $\mathrm{h}$ after the period of exposure (contact and ingestion) to azadirachtin and chlorantraniliprole, in addition to the distilled water-treated control. Imidacloprid and spinosad were not used in the sublethal (behavior) bioassays, due to $100 \%$ mortality by both contact and oral exposure obtained with the field label rates of these insecticides. The insects were exposed either by contact or ingestion, as previously described, and subsequently transferred to glass Petri dishes $(9.0 \mathrm{~cm}$ diameter) in groups of 10 workers bees from the same colony and three different colonies (i.e., replicates) of each species. The bottom of each Petri dish was covered with filter paper (Whatman no. 1), and the dish was covered with transparent plastic film to prevent insect escape. Activity recording was performed after a $1 \mathrm{~h}$ acclimation to the Petri dish arena to prevent confounding effects derived from insect handling. The overall insect activity was recorded for $10 \mathrm{~min}$ and digitally transferred to a video-tracking system equipped with a digital CCD camera (ViewPoint LifeSciences, Montreal, QC, Canada). The overall insect activity was recorded as changes in pixels between two subsequent pictures of the insect group, which were registered every $10^{-2} \mathrm{~s}$. The changes of quantified pixels between the subsequent pictures represented all movements within the arena (including walking, body part movements, and conspecific interactions) that were captured by the system every $10^{-2} \mathrm{~s}$. The bioassays were performed at $25 \pm 2^{\circ} \mathrm{C}$ and under artificial fluorescent light between 2:00 and 6:00 p.m.

\subsection{Flight take-off bioassay}

The workers subjected to the group activity bioassays were subsequently subjected to flight takeoff bioassays $25 \mathrm{~h}$ after the period of exposure. ${ }^{29}$ The same number of workers was used per replicate (i.e., 10) in three replicates (i.e., colonies) per treatment. A $105 \mathrm{~cm}$ tall tower was formed with three stacked wooden cages ( $35 \times 35 \times 35 \mathrm{~cm}$ each) opened in their interior to allow free 
insect flight through them. A fluorescent lamp was placed $15 \mathrm{~cm}$ above the top of the tower in a dark room. The flight take-off bioassay explored the vertical bee flight towards the light source after the insect release from the center bottom of the tower. The flight take-off was recorded within $1 \mathrm{~min}$ of worker release and was designated as follows: I) no flight (i.e., bee remained on the base of the tower), II) flight up to $35 \mathrm{~cm}$ high, III) flight between 36 and $70 \mathrm{~cm}$ high, IV) flight between 71 and $105 \mathrm{~cm}$ high, and V) flight reaching the light source at a height of $120 \mathrm{~cm}$.

\subsection{Statistical analyses}

The data from the time-mortality (survival) bioassays were subjected to survival analyses using Kaplan-Meier estimators to obtain the survival curves and estimates of the median survival time $\left(\mathrm{LT}_{50}\right)$ (PROC LIFETEST in SAS). ${ }^{30}$ The insects still alive at the end of the bioassays were treated as censored data. The overall similarity among survival curves (and estimated $L_{50} \mathrm{~s}$ ) was tested by the $\chi^{2}$ Log-Rank test, and the pairwise comparisons between curves were tested using the Bonferroni method. The data from the overall group activity were subjected to analyses of variance after being checked for normality and homoscedasticity (PROC UNIVARIATE from SAS) ${ }^{30}$, which were satisfied. The results of flight take-off were subjected to the (non-parametric) Kruskal-Wallis test ( $p$ $<0.05$ ) (PROC NPAR1WAY from SAS). ${ }^{30}$

\section{Results3.1 Time-mortality by contact exposure}

The survival of $P$. helleri and S. xanthotrica after insecticide contact exposure exhibited a significant difference among the treatments ( $P$. helleri: Log-rank $\chi^{2}=229.42, \mathrm{df}=4, p<0.001 ;$ S. xanthotrica: Log-rank $\chi^{2}=215.57, \mathrm{df}=4, p<0.001$ ) (Fig. 1(A,C)). Azadirachtin and chlorantraniliprole did not cause any mortality within $24 \mathrm{~h}$ among adult workers of $P$. helleri, resembling the untreated control (with only water application), but imidacloprid and spinosad caused $100 \%$ mortality within $5 \mathrm{~h}$ with median lethal times ( $\mathrm{LT} \mathrm{T}_{50} \pm \mathrm{SE}$ ) of $0.25 \pm 0.00 \mathrm{~h}$ and $1.00 \pm 0.14 \mathrm{~h}$, respectively (Fig. 1B). A similar trend was also observed for $S$. xanthotrica with azadirachtin and chlorantraniliprole exhibiting negligible mortality with $24 \mathrm{~h}$ exposure, and imidacloprid and spinosad leading to $100 \%$ mortality within $5 \mathrm{~h}$ of exposure $\left(\mathrm{LT}_{50} \pm \mathrm{SE}\right.$ of $0.25 \pm 0.00 \mathrm{~h}$ for imidacloprid and $4.00 \pm 0.00 \mathrm{~h}$ for spinosad) (Fig. 1D). $\mathrm{LT}_{50}$ 's for azadirachtin, chlorantraniliprole and untreated control were not shown because the mortality did not exceed $50 \%$, which is the minimum value that need to be reached throughout the time for estimation of such parameter. 


\section{Partamona helleri}

A

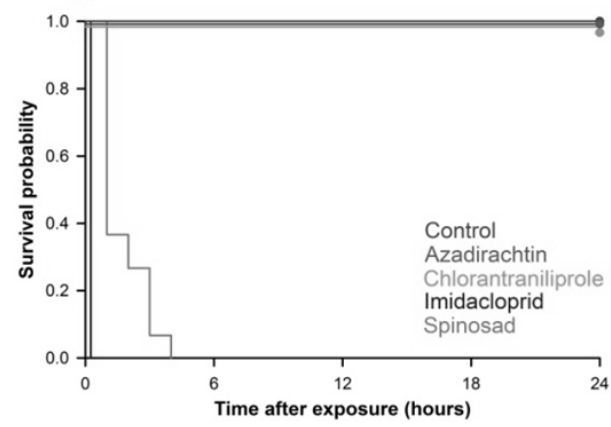

B

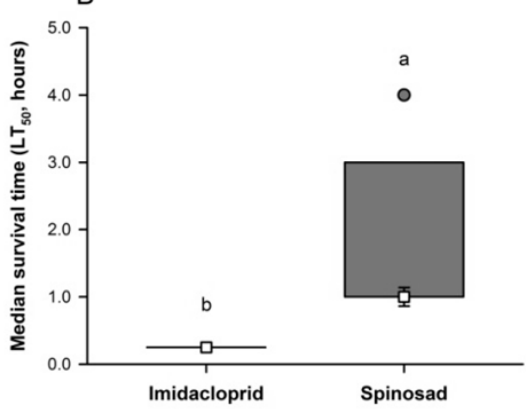

\section{Scaptotrigona xanthotrica}
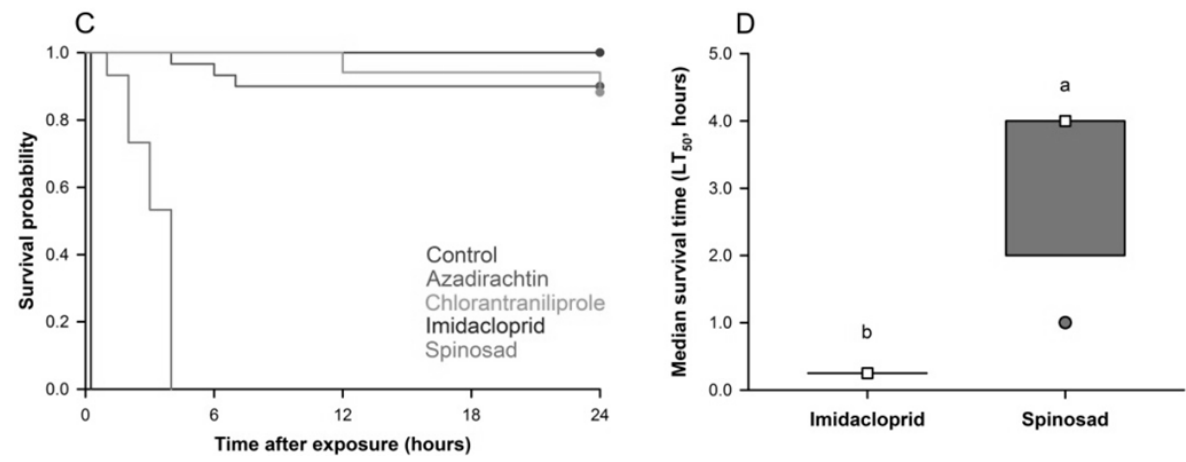

Figure 1 Survival curves $(\mathbf{A}, \mathbf{C})$ and box plots of the median survival times $\left(\mathrm{LT}_{50}{ }^{\prime} \mathrm{S}\right)(\mathbf{B}, \mathbf{D})$ of workers of the Neotropical stingless bee species Partamona helleri (A, B) and Scaptotrigona xanthotrica (C, D) contact-exposed to the field rates of commercial insecticides. Box plots indicate the median (line within the box), mean (open square with standard error bars) and range of dispersion (lower and upper quartiles, represented as the limits of the box, and outliers (symbol)) of the $\mathrm{LT}_{50} \mathrm{~s}$. The box plots with different lower case letters are significantly different by Bonferroni's method $(p<0.05)$.

\subsection{Time-mortality by oral exposure}

The survival curves of adult workers exposed to the insecticides by ingestion also exhibited trends similar to those obtained by contact exposure. The insecticides led to significant differences in the mortality profile of both $P$. helleri (Log-rank $\chi^{2}=189.24$, $\mathrm{df}=4, p<0.001$ ) and S. xanthotrica (Logrank $\chi^{2}=209.60, \mathrm{df}=4, p<0.001$ ) (Fig. $2(A, C)$ ). Azadirachtin and chlorantraniliprole led to negligible mortality for both stingless bee species, once again resembling the control. In contrast, imidacloprid and spinosad led quickly to $100 \%$ mortality of adult workers of $P$. helleri $\left(\mathrm{LT}_{50}{ }^{\prime} \mathrm{S} \pm \mathrm{SE}\right.$ of $0.25 \pm 0.03 \mathrm{~h}$ for imidacloprid and $2.00 \pm 0.00 \mathrm{~h}$ for spinosad) (Fig. $2 \mathrm{~B}$ ) and S. xanthotrica ( $\mathrm{LT}_{50}{ }^{\prime} \mathrm{S} \pm \mathrm{SE}$ of $0.25 \pm 0.00 \mathrm{~h}$ for imidacloprid and $2.00 \pm 0.00 \mathrm{~h}$ for spinosad) (Fig. 2D). 


\section{Partamona helleri}

A

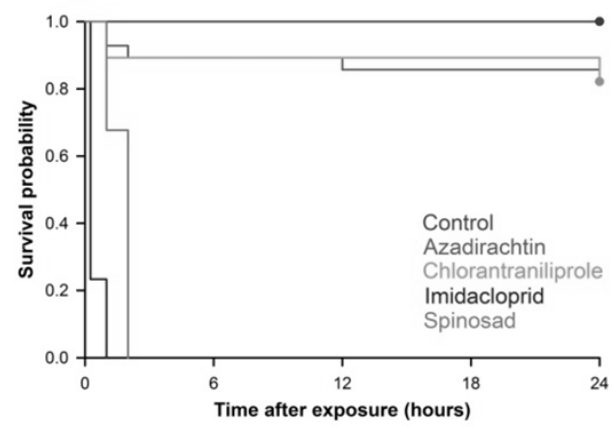

B

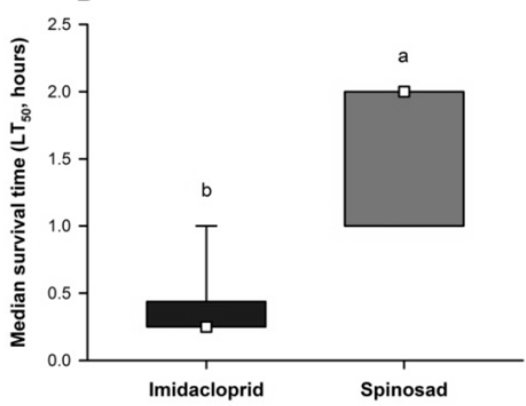

\section{Scaptotrigona xanthotrica}
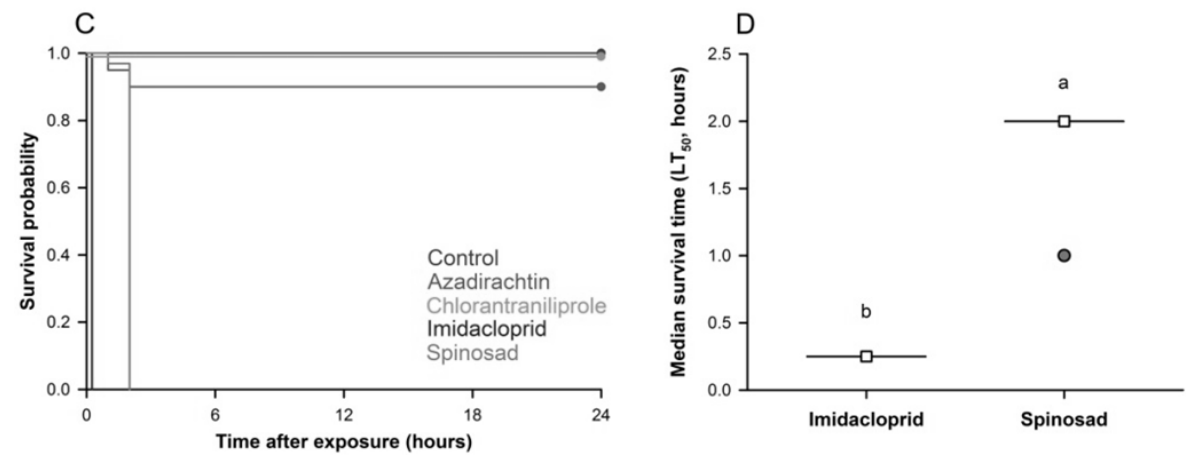

Figure 2 Survival curves $(\mathbf{A}, \mathbf{C})$ and box plots of the median survival times $\left(\mathrm{LT}_{50}{ }^{\prime} \mathrm{S}\right)(\mathbf{B}, \mathbf{D})$ of workers of the Neotropical stingless bee species Partamona helleri (A, B) and Scaptotrigona xanthotrica (C, D) orally-exposed to the field rates of commercial insecticides. Box plots indicate the median (line within the box), mean (open square with standard error bars) and range of dispersion (lower and upper quartiles, represented as the limits of the box, and outliers (symbol)) of the $\mathrm{LT}_{50} \mathrm{~s}$. The box plots with different lower case letters are significantly different by Bonferroni's method $(p<0.05)$.

\subsection{Overall group activity}

The group activity was assessed for azadirachtin- and chlorantraniliprole-exposed insects and unexposed insects (control), but no significant effect was detected $\left(F_{2,7}<1.45 p>0.31\right)$. The mean overall activity $\left( \pm \mathrm{SE}\right.$ ) was $46.70 \pm 13.56 \Delta$ pixels $/ \mathrm{s} \times 10^{-2}$ and $66.98 \pm 16.76 \Delta$ pixels $/ \mathrm{s} \times 10^{-2}$ for $P$. helleri among the treatments with contact and oral exposure, respectively, and $206.01 \pm 31.80 \Delta$ pixels $/ \mathrm{s} \times 10^{-2}$ and $302.35 \pm 23.33 \Delta$ pixels $/ \mathrm{s} \times 10^{-2}$ for $S$. xanthotrica among the treatments with contact and oral exposure, respectively.

\subsection{Flight take-off activity}

Contact exposure to azadirachtin did not affect the take-off flight of $P$. helleri $(\mathrm{H}=0.40, \mathrm{df}=1, p=$ 0.53) (Fig. 3A), whreas chlorantraniliprole significantly impaired such flight preventing bees from reaching the light source $(\mathrm{H}=4.50, \mathrm{df}=1, p=0.03)$ (Fig. 3B). In contrast, both insecticides impaired flight take-off of S. xanthotrica $(H>13.40, \mathrm{df}=1, p<0.001)$ (Fig. $3(\mathrm{C}, \mathrm{D})$ ). 


\section{Partamona helleri}

A

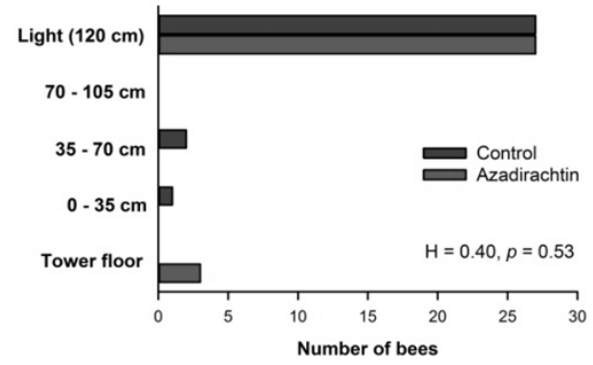

B

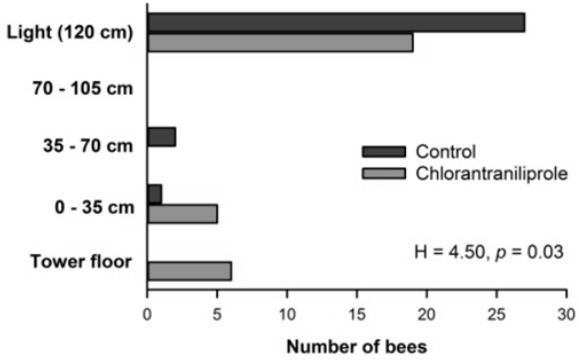

Scaptotrigona xanthotrica

C

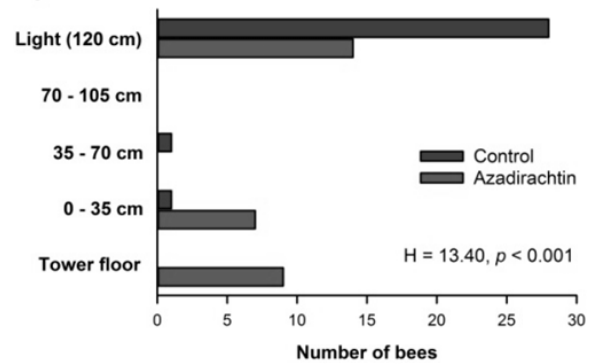

$\mathrm{D}$

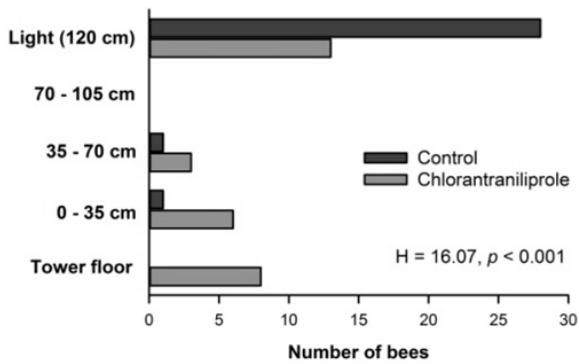

Figure 3 Flight take-off activity of adult workers of the Neotropical stingless bee species Partamona helleri (A, B) and Scaptotrigona xanthotrica (C, D) contact-exposed to the field rates of the commercial insecticides azadirachtin $(\mathbf{A}, \mathbf{C})$ and chlorantraniliprole $(\mathbf{B}, \mathbf{D})$. The results of the (non-parametric) Kruskal-Wallis test ( $p<$ $0.05)$ used to test the differences between untreated and insecticide-treated insects are indicated.

Oral ingestion of either azadirachtin or chlorantraniliprole impaired flight take-off by $P$. helleri $(\mathrm{H}>$ 4.98, $\mathrm{df}=1, p \leq 0.02$ ), reducing the number of individuals taking-off for flight and the number reaching the light source (Fig. $4(A, B)$ ). By contrast, there was no significant effect of azadirachtin and chlorantraniliprole on $S$. xanthotrica regarding their flight take-off activity $(\mathrm{H} \leq 1.16, \mathrm{df}=1, p \geq$ 0.28) (Fig. 4(C,D)). 
Partamona helleri

A

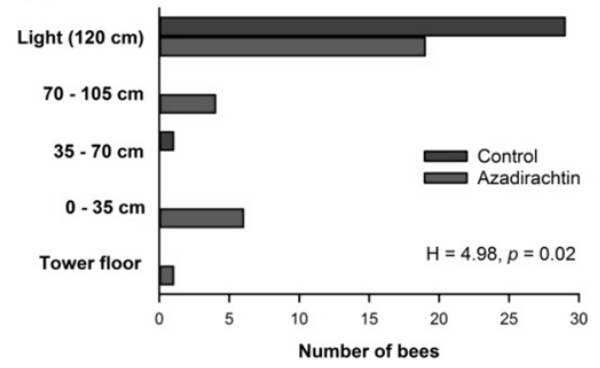

B

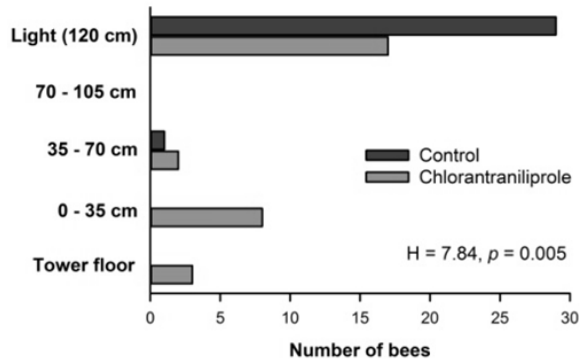

Scaptotrigona xanthotrica
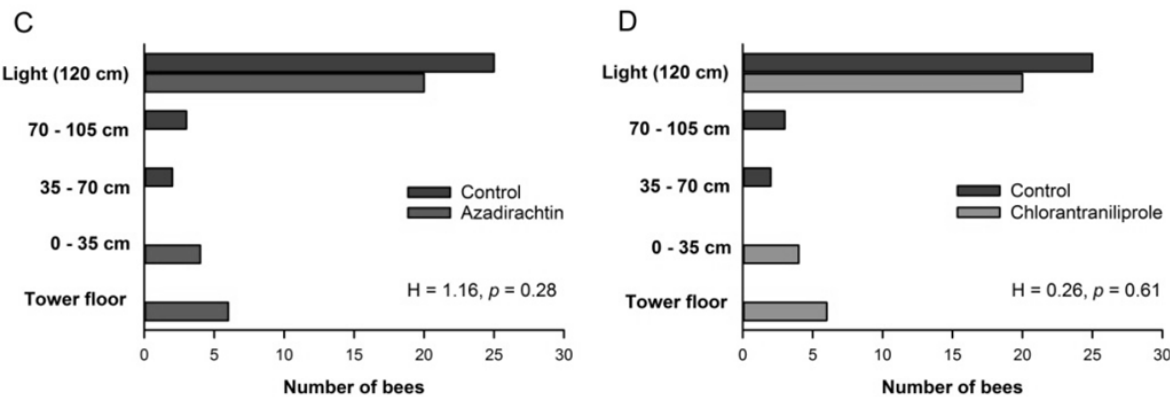

Figure 4 Flight take-off activity of adult workers of the Neotropical stingless bee species Partamona helleri (A, B) and Scaptotrigona xanthotrica (C, D) orally-exposed to the field rates of the commercial insecticides azadirachtin (A, C) and chlorantraniliprole (B, D). The results of the (non-parametric) Kruskal-Wallis test $(p<$ 0.05 ) used to test the differences between untreated and insecticide-treated insects are indicated.

4. DiscussionThe susceptibility of stingless bees to modern substances defined as reduced-risk insecticides, including bioinsecticides, has received little attention. Here we observed that spinosad is highly toxic at $20.4 \mathrm{mg} \mathrm{litre}^{-1}$ to both stingless bee species tested, $P$. helleri and $S$. xanthotrica, causing quick and complete mortality of the worker bees within $5 \mathrm{~h}$ of either contact or oral exposure. Only imidacloprid exhibited more rapid mortality of workers than spinosad, regardless of the exposure method.

The terpenoid bioinsecticide azadirachtin caused negligible adult mortality in both species of stingless bees used in this study, similar to the reduced-risk diamide insecticide chlorantraniliprole. The low acute mortality caused by azadirachtin and chlorantraniliprole was expected, because the former usually requires very high doses to achieve repellence and impair development in Hymenoptera, ${ }^{31}$ and the latter exhibits insecticidal activity limited to caterpillars, flies and beetles, 32,33 with low toxicity against honeybees and bumblebees at the recommended field label rate. ${ }^{34,35}$ The differential ryanodine receptor sensitivity to chlorantraniliprole in bee pollinators is the likely reason for the low acute toxicity of this insecticide to bee species, ${ }^{33,36}$ whereas the reasons for the low azadirachtin acute toxicity to pollinators have not yet been studied.

As sublethal exposure may also compromise insect survival and reproduction of bees, the sublethal responses of $P$. helleri and $S$. xanthotrica to azadirachtin and chlorantraniliprole were also assessed. Here, azadirachtin and chlorantraniliprole did not affect overall group activity of workers, which is an important trait since represents insect-insect interactions and individual activity within a group of social bees. However, flight take-off of $P$. helleri was impaired by chlorantraniliprole, and the flight take-off of $S$. xanthotrica was impaired by azadirachtin and chlorantraniliprole, regardless of the route of exposure. Neither compound has been reported to impair pollinator activity, unlike 
neonicotinoids in honeybees, ${ }^{37,38}$ and neonicotinoids and pyrethroids in bumblebees. ${ }^{39,40}$ However, azadirachtin and chlorantraniliprole have not been subjected to such studies, which is likely due to their perceived (although questionable) overall environmental safety. Nonetheless, the azadirachtin interference with the availability of brain neurosecretory peptides and the chlorantraniliprole interference with muscle activity may allow for the flight take-off impairment. 31,32

Our findings partially support the perceived notion of the environmental safety of azadirachtin and chlorantraniliprole at their recommended field rates in a worst case scenario, which is reinforced by their recognition as reduced-risk insecticides (or bioinsecticide, in the case of azadirachtin). However, such a perception is not valid for spinosad, another reduced-risk (bio)insecticide, which exhibited high acute lethality to the two stingless bee species tested, resembling the drastic and broadly recognized toxicity of imidacloprid to pollinators. ${ }^{41-44}$ Furthermore, azadirachtin and chlorantraniliprole impaired the flight take-off of stingless bees, potentially impairing foraging and compromising colony survival, as may happened with honeybees under sublethal impact of neonicotinoids. ${ }^{36,45}$ Therefore, the perceived notion of pollinator safety associated with reduced-risk insecticides is misleading; low toxicity to non-target species is only one of the alternative requirements (which are fairly broad) allowing the recognition of a given insecticide as a reduced-risk compound. ${ }^{16}$ Regarding bioinsecticides, origin is not a determinant of toxicity, and the perceived safety of such compounds is again a misconception. The proper assessment of such compounds should not be neglected by being labeled as reduced-risk insecticides and/or as bioinsecticides before a proper assessment has been performed.

\section{Acknowledgements}

Thanks the Arthur Bernardes Foundation (Funarbe), the Minas Gerais State Foundation for Research Aid (FAPEMIG), the National Council of Scientific and Technological Development (CNPq), and the CAPES Foundation for the financial support provided. The comments and suggestions provided by the editor and two anonymous reviewers were also greatly appreciated.

\section{References}

1 Schacker M, A Spring without Bees: How Colony Collapse Disorder Has Endangered our Food Supply. Ed by: Lyon Press, Guilford, Connecticut, USA (2009).

2 Tirado R, Simon G, Johnston P, Bees in Decline: A Review of Factors that Put Pollinators and Agriculture in Europe at Risk. ed by Greenpeace International Amsterdam, The Netherlands (2013).

3 Porrini C, Sabatini AG, Girotti S, Fini F, Monaco L, Celli G, Bortolotti L, Ghini S, The death of honey bees and environmental pollution by pesticides: the honey bees as biological indicators. B Insectol 56:147-152 (2003).

4 Klein AM, Vaissière BE, Cane JH, Steffan-Dewenter I, Cunningham SA, Kremen C, Tscharntke T, Importance of pollinators in changing landscapes for world crops. Proc R Soc B 274:303-313 (2007).

5 Arena M, Sgolastra F, A meta-analysis comparing the sensitivity of bees to pesticides. Ecotoxicology 23, 324-334 (2014).

6 Tomé HVV, Martins GF, Lima MAP, Campos LAO, Guedes RNC, Imidacloprid-induced impairment of mushroom bodies and behavior of the native stingless bee Melipona quadrifasciataanthidioides. PLoS ONE 7:e38406 (2012).

7 van der Valk H, Koomen I Aspects Determining the Risk of Pesticides to Wild Bees: Risk Profiles for Focal Crops on Three Continents. Pollination Services for Sustainable Agriculture - Field Manuals. FAO, Rome, Italy (2013).

8 Del Sarto MC, Oliveira EE, Guedes RNC, Campos LAO, Differential insecticide susceptibility of the Neotropical stingless bee Melipona quadrifasciata and the honey bee Apis mellifera. Apidologie 45:626-636 (2014).

9 Roubik DW, Pollinator Safety in Agriculture. FAO, Rome, Italy (2014).

10 Slaa EJ, Sanchez-Chaves LA, Malagodi-Braga KS, Hofstede FE, Stingless bees in applied pollination: practice and perspectives. Apidologie 37:293-315 (2006).

11 Palma G, Quezada-Euán JJG, Melendez-Ramirez V, Irigoyen J, Valdovinos-Nuñez GR, Rejón M, Comparative efficiency of Nannotrigona perilampoides, Bombus impatiens (Hymenoptera: Apoidea), and mechanical vibration on fruit production of enclosed habanero pepper. J Econ Entomol 101:132-138 (2008).

12 Bispo dos Santos SA, Roselino AC, Hrncir M, Bego LR, Pollination of tomatoes by stingless bee Melipona quadrifasciata and the honey bee Apis mellifera (Hymenoptera: Apidae). Genet Mol Res 8:751-757 (2009).

13 Winfree R, Williams NM, Dushoff J, Kremen C, Native bees provide insurance against ongoing honey bee losses. Ecol Lett 10:1105-1113 (2007). 
14 Brosi BJ, Briggs HM, Single pollinator species losses reduce floral fidelity and plant reproductive function. Proc Natl Acad Sci USA 110:13044-13048 (2013).

15 US Environmental Protection Agency [EPA] Biopesticides. Washington, DC, US: US EPA (2014a). [cited 19 July 2014]. Available from: http://www.epa.gov/oecaagct/tbio.html.

16 US Environmental Protection Agency [EPA] Pesticides: Regulating Pesticides. Washington, DC, US: US EPA (2014b). [cited 19 July 2014]. Available from: http://www.epa.gov/opprd001/workplan/reducedrisk.html.

17 Villaverde JJ, Sevilla-Morán B, Sandín-España P, López-Goti C, Alonso-Prados JL, Biopesticides in the framework of the European Pesticide Regulation (EC) No. 1107/2009. Pest Manag Sci 70:2-5 (2014).

18 Gerwick BC, Sparks TC, Natural products for pest control: an analysis of their role, value and future. Pest Manag Sci 70:11691185 (2014).

19 Agriculture and Agri-Food Canada, Pesticide Risk Reduction and Minor Use Programs: Improving ways to Manage Pests with New Technology. Ottawa, ON, Canada: Government of Canada (2003). [cited 19 July 2014]. Available from: https://archive.org/details/pesticideriskred00otta.

20 Jones E, Grants Awarded to Develop Pesticide Risk Reduction Programs Washington, US EPA, DC, US (2004). [cited 19 July 2014]. Available from: http://yosemite.epa.gov/opa/admpress.nsf/d0cf6618525a9efb85257359003fb69d/738ef661407a042085257035005831d b!OpenDocument\&Highlight=2,risk.

21 Bahlai CA, Xue Y, McCreary CM, Schaafsma AW, Hallett RH, Choosing organic pesticides over synthetic pesticides may not effectively mitigate environmental risks in soybeans. PLOS ONE 5:e11250 (2010).

22 Biondi A, Desneux N, Siscaro G, Zappalà L, Using organic-certified rather than synthetic pesticides may not be safer for biological control agents: selectivity and side effects of 14 pesticides on the predator Orius laevigatus. Chemosphere 87:803-812 (2012a).

23 Biondi A, Mommaerts V, Smagghe G, Viñuela E, Zappalà L, Desneux N, The non-target impact of spinosyns on beneficial arthropods. Pest Manag Sci 68:1523-1536 (2012b).

24 Isman MB, Grieneisen ML, Botanical insecticide research: many publications, limited useful data. Trends Plant Sci 19:140-145 (2014).

25 Brosi BJ, Briggs HM, Single pollinator species losses reduce floral fidelity and plant reproductive function. Proc Natl Acad Sci USA 110:13044-13048 (2013).

26 Blacquière T, Smagghe G, van Gestel CAM, Mommaerts V, Neonicotinoids in bees: A review on concentrations, side-effects and risk assessment. Ecotoxicology 21:973-992 (2012).

26 Ministério da Agricultura, Pecuária e Abastecimento [MAPA] Agrofit. Brasília, DF, Brazil: Coordenação Geral de Agrotóxicos e Afins/DFIA/DAS (2014). [cited 19 July 2014]. Available from: http://extranet.agricultura.gov.br/agrofit_cons/principal_agrofit_cons.

27 Topp E, Smith W Sorption of the herbicides atrazine and metolachlor to selected plastics and silicone rubber. J Environ Qual 21:316-317 (1992).

2853 Nerin C, Tornés AR, Domeño C, Cacho J, Absorption of pesticides on plastic films used as agricultural soil covers. J Agric Food Chem 44:4009-4014 (1996).

29 Tomé HVV, Barbosa WF, Martins GF, Guedes RNC, Spinosad in the native stingless bee Melipona quadrifasciata: Regrettable non-target toxicity of a bioinsecticide. Chemosphere 124:103-109 (2015).

30 SAS Institute Inc. SAS/STAT 9.2 User's Guide. SAS Institute Inc. Cary, NC (2008).

31 Mordue (Luntz) AJ, Nisbet AJ, Azadirachtin from the neem tree (Azadirachta indica): its actions against insects. An Soc Entomol Bras 29:615-632 (2000).

32 Cordova D, Benner EA, Sacher MD, Rauh JJ, Sopa JS, Lahm GP, Selby TP, Stevenson TM, Flexner L, Gutteridge S, Rhoades DF, Wu L, Smith RM, Tao Y, Anthranilicidiamides: a new class of insecticides with a novel mode of action, ryanodine receptor activation. Pest Manag Sci 84:196-214 (2006).

33 Brugger KE, Cole PG, Newman IC, Parker IC, Scholz B, Suvagia P, Walker G, Hammond TG, Selectivity of chlorantraniliprole to parasitoid wasps. Pest Manag Sci 66:1075-1081 (2010).

34 Gradish AE, Scott-Dupree CD, Shipp L, Harris CR, Fergunson G, Effect of reduced risk pesticides for use in greenhouse vegetable production on Bombus impatiens (Hymenoptera: Apidae). Pest Manag Sci 66:142-146 (2010).

35 Larson JL, Redmond CT, Potter DA, Assessing insecticide hazard to bumble bees foraging on flowering weeds in treated lawns. PLOS ONE 8:e66375 (2013).

36 Yang EC, Chuang YC, Chang LH, Abnormal foraging behavior induced by sublethal dosage of imidacloprid in the honey bee (Hymenoptera: Apidae). J Econ Entomol 101:1743-1748 (2008).

37 Schneider CW, Tautz J, Grünewald B, Fuchs S RFID tracking of sublethal effects of two neonicotinoid insecticides on the foraging behavior of Apis mellifera. PLOS ONE 7:e30023 (2012).

38 Fischer J, Müller T, Spatz A-K, Greggers U, Grünewald B, Neonicotinoids interfere with specific components of navigation in honeybees. PLOS ONE 9:e91364 (2014).

39 Gill RJ, Ramos-Rodriguez O, Raine NE, Combined pesticide exposure severely affects individual- and colony-level traits in bees. Nature 491, 105-108 (2012).

40 Gill RJ, Raine NE, Chronic impairment of bumblebee natural foraging behavior induced by sublethal pesticide exposure. Funct Ecol 28:1459-1471 (2014). 
41 Chauzat M-P, Laurent M, Riviere M-P., Saugeon C, Hendrikx P, Ribire-Chabert M, Epilobee - A Pan-European Epidemiological Study on Honeybee Colony Losses 2012-2013. European Union Reference Laboratory for Honeybee Health (EURL), Sophia Antipolis, France (2014).

42 Godfray HCJ, Blacquière T, Field LM, Hais RS, Petrokofsky G, Potts SG, Raine NE, Vanbergen AJ, McLean AR, A restatement of the natural science evidence base concerning neonicotinoid insecticides and insect pollinators. Proc Royal Soc $B$ 281:20140558 (2014).

43 Johnson RM, Dahlgren L, Siegfried BD, Ellis MD, Acaricide, fungicide and drug interactions in honey bees (Apis mellifera). PLOS ONE 8:e54092 (2013).

44 Zhu W, Schmehl DR, Mullin CA, Frazier JL, Four common pesticides, their mixtures and a formulation solvent in the hive environment have high oral toxicity to honey bee larvae. PLOS ONE 9:e77547 (2014).

45 Henry M, Béguin M, Requier F, Rollin O, Odoux JF, Aupinel P, Aptel J, Tchamitchian S, Decourtye A, A common pesticide decreases foraging success and survival in honey bees. Science 336:348-350 (2012). 